\title{
O Revenge Porn no Brasil e as Consequências da Criminalidade Digital Para os Direitos Humanos de Crianças e Adolescentes: Uma análise a partir das decisões do Superior Tribunal de Justiça
}

\section{Felipe da Veiga Dias}

Pós-doutor em Ciências Criminais pela PUC/RS. Doutor em Direito pela Universidade de Santa Cruz do Sul (Unisc) com período de doutorado-sanduíche na Universidad de Sevilla (Espanha). Professor do Programa de Pós-Graduação em Direito (Mestrado) e do curso de Direito da Faculdade Meridional (Imed) - Passo Fundo/RS, Brasil. Coordenador do Grupo de Pesquisa "Criminologia, Violência e Sustentabilidade Social” (Imed). Advogado. http://lattes.cnpq.br/6961580388113058. felipevdias@gmail.com

\section{Iuri Bolesina}

Doutor e mestre em Direito pela Universidade de Santa Cruz do Sul - Unisc. Especialista em Direito Civil pela Faculdade Meridional (Imed). Coordenador e professor da Faculdade Meridional - Imed. Advogado. http://lattes.cnpq.br/8192666406729110.

iuribolesina@gmail.com

O estudo em pauta tem como tema o revenge porn e os direitos humanos de crianças e adolescentes, de modo que para delimitar a abordagem especifica-se a pesquisa a partir das decisões do Superior Tribunal de Justiça no período entre 2014 e 2016. Assim, adota-se como problema de pesquisa como e de que maneira são atingidos os direitos humanos de crianças e adolescentes por meio do revenge porn, bem como de que modo se dá a resposta judicial a tais demandas. Esse questionamento busca ser respondido com auxílio do método indutivo de abordagem, juntamente com o método de procedimento monográfico e da técnica de pesquisa da documentação indireta. Desse modo, conclui-se que direitos humanos de crianças e adolescentes encontram-se atingidos pela conduta do revenge porn, tais como dignidade humana, direitos de personalidade e liberdade. Ademais, por vezes, o revenge porn é auxiliado por outros crimes digitais (sexting e ciberbullying), gerando danos sociais, físicos e psicológicos aos infantes, além de atualmente contar com respostas simplificadas e insuficientes tanto na via jurisdicional quanto política, uma vez que não existe um planejamento para atuações em relação ao tema, tampouco se observa a compreensão de ações que superem as respostas punitivas ou demagógicas.

Palavras-chave: Revenge porn. Direitos humanos. Crianças e adolescentes.

REVENGE PORN IN BRAZIL AND THE CONSEQUENCES OF THE DIGITAL CRIMINALITY FOR THE HUMAN RIGHTS OF CHILDREN AND ADOLESCENTS: AN ANALYSIS FROM THE DECISIONS OF THE SUPERIOR COURT OF JUSTICE

The study in question has the theme revenge porn and the human rights of children and adolescents, so that to delimit the approach is specified the research from the decisions of the Superior Court of Justice in the period between 2014 and 2016. Thus, adopts as a research problem how and in what way human rights of children and adolescents are achieved through revenge porn, and how the judicial response to such demands is achieved. This questioning seeks to be answered with the aid of the inductive approach method, together with the monographic procedure method and the research technique of indirect documentation. In this way, it can be concluded that human rights of children and adolescents are affected by the conduct of revenge porn, such as human dignity, personality rights and freedom. In addition, sometimes revenge porn is aided by other digital crimes (sexting and cyberbullying), generating social, physical and psychological damages to infants, and currently has simplified and insufficient answers both in the jurisdictional and political routes, since there is no planning for actions in relation to the theme, nor is there an understanding of actions that overcome punitive or demagogic responses.

Keywords: Revenge porn. Human rights. Children and adolescents.

SUMÁRIO

1 Introdução. 2 O Revenge Porn Segundo a Leitura do Superior Tribunal de Justiça de 2014 a 2016. 3 O Revenge Porn Como Ato de Violência Contra a Infância. 4 Enfrentamento da Criminalidade Contra Crianças e Adolescentes na Internet: Sexting, Ciberbullying, Revenge Porn e Novas Formas de Violência On-line. 5 Conclusão. 6 Referências. 


\section{INTRODUÇÃO}

O presente estudo adota como tema o revenge porn (ou pornô de vingança) e as afetações aos direitos humanos de crianças e adolescentes, tendo como ponto de partida as decisões do Superior Tribunal de Justiça. Isso significa que apesar de o debate encontrar-se situado em um ambiente global, tentar-se-á concentrar os efeitos no âmbito nacional, a fim de compreender as ferramentas disponíveis diante das violações ocorridas e quais os instrumentos de ação a partir desse mesmo contexto.

Assim, tem-se como questionamento de pesquisa, como e de que maneira são atingidos os direitos humanos de crianças e adolescentes por meio do revenge porn, bem como de que modo se dá a resposta judicial a tais demandas.

Essa reflexão encontra-se inserida na dinâmica das novas demandas advindas do processo de inserção digital, a qual é considerada necessidade educativa na formação de crianças e adolescentes, mas traz consigo toda uma nova gama de riscos inerentes a tal atuação. Em síntese, as vantagens comunicativas e de acesso à informação com o uso da Internet comportam igualmente outras maneiras de lesar direitos humanos de crianças e adolescentes, uma vez que ocorre a ampliação dos espaços de desenvolvimento de relações sociais e, por conseguinte, os abusos se modificam para adaptar-se a outros formatos.

A fim de responder às indagações projetadas, adota-se como metodologia de abordagem o estudo indutivo, tomando-se inicialmente as decisões do Superior Tribunal de Justiça para, com base nos casos concretos, traçar considerações mais abrangentes sobre o revenge porn e os danos a infantes. Junto ao método de abordagem colaciona-se o método de procedimento monográfico, visto que não se pretender realizar um estudo dogmático ao estilo de um manual, ou seja, almeja-se o aprofundamento em uma reflexão pontual sobre o tema escolhido.

Por fim, cabe menção à técnica de pesquisa que se soma aos métodos supramencionados, de documentação indireta com ênfase bibliográfica. Nesse sentido, são utilizados livros, artigos e pesquisas de dados sobre o revenge porn e sua atuação contra crianças e adolescentes, destacando-se que tais fontes são adicionadas aos julgados do Superior Tribunal de Justiça na averiguação da resposta judicial a essa nova demanda da infância no país.

\section{REVENGE PORN SEGUNDO A LEITURA DO SUPERIOR TRIBUNAL DE JUSTIÇA DE 2014 A 2016}

A apreciação do tema do revenge porn pelo Superior Tribunal de Justiça parte da definição das palavras-chave para a busca, sendo salutar enfatizar que as bases deste estudo não revelaram nenhuma ocorrência, ou seja, a tentativa de localização com base nos termos "revenge porn" ou "pornô de vingança" não resultaram em ocorrências conforme o sistema de decisões da Corte.

Diante da negativa inicial, a qual denota uma primeira consideração, de que o termo central do estudo ainda não é adotado no debate judicial, passou-se a traçar alternativas. Nesse norte optou-se por buscar os termos "vídeo" e "ex-namorado", os quais remetem à essência do termo original, embora possam abarcar situações similares, obtendo-se como resultado três decisões, as quais se situam entre os anos de 2014 e 2016 (BRASIL, 2017a). 


\section{Democracia}

A adoção de termos mais abrangentes como "Internet" e "imagens íntimas" aumentou o volume de ocorrências para 13, porém surgiram situações completamente afastadas do assunto em debate, tais como casos de homicídio ou extorsão, os quais não detinham nenhuma relação com questões afetivas ou mesmo sexuais, tampouco com conflitos realmente situados no universo da Internet (na grande maioria a rede mundial de computadores aparece apenas como menção ao dispositivo de divulgação de informações ou imagens sem, contudo, detalhar a sua relevância para o caso concreto) (BRASIL, 2017b). Ademais, como havia outro fator de especificidade, crianças e adolescentes, restava a necessidade de inserir este público na busca em apreço.

Com base na carência supramencionada definiram-se os termos "nudez", "vídeo" e "adolescentes", obtendo-se outros três resultados distintos da primeira linha de busca (BRASIL, 2017c), fator este que indicou uma boa delimitação de tempo, uma vez que inexistem decisões sobre o assunto anteriores a 2014 e, no corrente ano , ainda não foram documentadas ocorrências no Superior Tribunal de Justiça envolvendo infantes e a divulgação de conteúdos íntimos.

Situam-se, portanto, cerca de duas decisões por ano, cada uma delas resultante da primeira e terceira busca, consequentemente. Seguindo a ordem cronológica, passa-se ao exame das decisões aludidas, começando pelo ano de 2014, mais precisamente com o habeas corpus n. 298504 (Caso 1), o qual foi impetrado contra ordem que determinou a prisão preventiva de um policial militar acusado de praticar os crimes de pornografia infantil (artigo 241-B do Estatuto da Criança e do Adolescente), aliciamento para fins libidinosos (artigo 241-D do Estatuto da Criança e do Adolescente) e tentativa de estupro (artigo 213 do Código Penal) (BRASIL, 2014a).

Na situação em apreço não existia um relacionamento entre os envolvidos, mas se trata da divulgação de imagens íntimas da adolescente no ambiente on-line, em realidade, a ocorrência do julgado se dá em razão das tentativas de coerção da vítima (adolescente) terem ocorridos via rede social (Facebook), bem como as condutas realizadas serem compatíveis com fatos usualmente desempenhados nos casos de revenge porn. Em resumo, apesar de não existir uma relação entre os envolvidos, havia a tentativa de coerção pela divulgação das imagens da adolescente nua, como forma de compelir à execução de atos sexuais ou libidinosos com o acusado (BRASIL, 2014a).

Embora o autor da conduta não tenha conseguido perfectibilizar o ato de proliferação do conteúdo por circunstâncias alheias a sua vontade (intervenção da genitora da adolescente junto a unidade de Crimes Cibernéticos), claramente, conforme apresentam os ministros do Superior Tribunal de Justiça, ele realizou a conduta contra mais de um infante de forma reiterada, bem como utilizou-se da sua posição (e dos materiais) como agente do Estado (capitão da polícia) para perpetrar a sua ação (BRASIL, 2014a).

Neste primeiro caso podem-se inferir algumas considerações: a) o fato realizado e as condutas anteriores (reiteração por parte do autor) imputadas foram todas perpetradas contra adolescentes do sexo feminino; b) a Internet foi utilizada como mero veículo para realização das ameaças e para coagir a vítima; c) não houve a exposição das imagens íntimas na rede, pois toda a estrutura de aliciamento para prática de atos sexuais ou libidinosos baseava-se no temor pela divulgação e não em um intuito de humilhar ou punir a vítima. 
A segunda decisão, ainda no ano de 2014, trata de um Recurso Especial n. 1475686 (Caso 2), todavia encontra-se aqui um falso resultado positivo. Explica-se: na situação em concreto ocorreu um estupro com presunção de violência (anterior à legislação atual em que a presunção é absoluta), tendo o réu sido absolvido, uma vez que a vítima tinha experiência sexual e consentiu com os atos praticados. Apesar de apresentar posicionamento considerável acerca da visão dos ministros sobre a vítima em crimes sexuais (há claramente a apreciação da vida sexual pregressa da vítima como forma de exclusão da responsabilidade do autor maior de idade), não há qualquer menção a conteúdos íntimos, à Internet ou mesmo a registro de atos sexuais ou libidinosos entre as partes (BRASIL, 2014b).

Logo, o aparecimento do julgado ocorreu tão somente porque o acusado deu um "vídeo" game à vítima, e foi relatado um relacionamento anterior com outro adolescente, fazendo menção à palavra "ex-namorado", gerando assim ao menos duas palavras de busca diferentes, mas que não se encontravam no contexto da pesquisa, motivo pelo qual se deixa de apreciar tal decisão.

Em continuidade, já no ano de 2015, ocorre novo resultado descartável, mais especificamente o habeas corpus n. 324343 (Caso 3), tendo em vista que o paciente tenta mover a ação impugnativa para impedir a sua prisão preventiva, em razão das acusações de possuir e divulgar materiais contendo infantes em cenas sexuais ou libidinosas na Internet. Inexiste, entretanto, na narrativa menção a vítimas, de forma que o caso não possui sujeitos identificados (não existe relação entre autor e vítimas), e embora o autor esteja sendo processado criminalmente, não há relato sobre as crianças ou adolescentes envolvidos, o que acaba por impossibilitar uma análise mais aprofundada da questão (BRASIL, 2015a).

No segundo julgado do mesmo ano com base em um Conflito de Competência n. 13455 (Caso 4), havia a ocorrência de fatos criminosos contra crianças e adolescentes que contavam com o compromisso internacional do país em coibi-los (violação de ordem sexual envolvendo criança ou adolescente, bem como delitos ligados à pedofilia e pornografia infantil), por meio de tratados de direitos humanos. Com base no caráter transnacional dos crimes realizados on-line contra infantes, consolidou-se o embate em torno da competência da matéria (BRASIL, 2015b).

Transpassado o viés decisório acerca da competência federal da matéria, restou evidenciado que, no caso, um adolescente após o término de um relacionamento divulgou em dois sites - Youtube e Xvideos - vídeo envolvendo ele e sua ex-namorada, também adolescente, em cena de sexo. "Quando do término do namoro, o investigado passou a ameaçar a ex-namorada de que iria expor o vídeo na Internet caso não reatassem o relacionamento", fato este que se consumou, sendo posteriormente retirado do ar o vídeo do site Youtube, porém o mesmo não ocorreu em relação ao segundo endereço eletrônico (Xvideos), o qual se encontra hospedado fora do país (BRASIL, 2015b).

$O$ adolescente autor das infrações foi imputado pelos artigos 241-A do Estatuto da Criança e do Adolescente e 147 do Código Penal, haja vista que postou em dois sites diferentes vídeo contendo menores de idade realizando atos sexuais ou libidinosos, e em especial, no caso concreto, realizou tal ato a fim de coagir a vítima a retomar um relacionamento, usando de ameaças contra ela (BRASIL, 2015b). 


\section{Democracia}

Nesse sentido, apura-se que: a) apesar de não ser o autor da infração um produtor ou consumidor regular de material pornográfico envolvendo infantes, acabou por realizar o disposto no tipo penal a fim de atingir a vítima expondo sua intimidade on-line; b) a Internet é relatada como um meio de divulgação dos materiais e que pode ter amplitude de acesso global; c) novamente o ato se perpetuou contra adolescente do sexo feminino, por parte de autor do sexo masculino; d) a coação tinha a finalidade de obrigar a vítima a reatar relacionamento findado, sendo a ameaça pautada na humilhação e temor causado pela divulgação do material íntimo do casal.

Os dois últimos julgados ocorreram no ano de 2016, com o primeiro sendo novamente passível de descarte, tendo ocorrido um Agravo em Recurso Especial n. 828064 (Caso 5), contando com situação de posse e divulgação de material pornográfico contendo crianças e adolescentes (artigo 241 - A do Estatuto da Criança e do Adolescente) (BRASIL, 2016a), porém, tal qual a situação do Caso 3 de 2015, inexiste no processo relato específico sobre vítimas, não há imputação de quem ou quantas pessoas teriam sido lesadas, tampouco existia relação entre autor e vítimas, fatos estes que incompatibilizam a apreciação do caso junto ao tema do estudo.

Por fim, a última decisão diz respeito ao habeas corpus n. 361038 (Caso 6), no qual Sidney chantageou sua ex-namorada para realização de atos sexuais sob a ameaça de divulgação de cenas íntimas do casal, o qual não mantinha mais o relacionamento. $O$ acusado, inclusive, chegou a confirmar as ameaças ao expor vídeo/fotografia na rede social "Aloja Insano", a fim de manter a atuação criminosa contra a vítima (BRASIL, 2016b).

Apesar de o caso em apreço tratar de situação tipicamente enquadrada no assunto em debate, acaba por não lidar com o envolvimento de crianças ou adolescentes, motivo pelo qual não traz contribuição pontual à pesquisa. Cabe mencionar, entretanto, que a posição dos ministros foi de enfatizar que a conduta realizada supera os limites da violação jurídico-penal, consumando-se em infração ética considerável, pois expôs "odiosamente a privacidade dela, em claro desrespeito aos mais comezinhos predicados de ética, moralidade e decência" (BRASIL, 2016b).

Assim sendo, o quadro a priori projetado pelos casos apreciados no Superior Tribunal de Justiça denota que diante da ausência de previsão específica sobre as violações da intimidade sexual, os fatos que envolvem a divulgação de vídeos ou fotografias de crianças e adolescentes vêm sendo coibidos com base em figuras já previstas do Estatuto da Criança e do Adolescente (artigos 241-A, B e D), sendo ainda aplicados dispositivos residuais do Código Penal. Isso indica que a parca compreensão do fenômeno do revenge porn não impede a atuação coercitiva do Estado, ao menos nos casos demandados até o momento, por parte da Corte. Embora se deva apontar que a falta de uma imputação específica pode causar a ausência de adequação típica da conduta, isso conduz à mera cogitação com base na concepção da cifra negra da criminalidade. ${ }^{1}$

\footnotetext{
${ }^{1}$ [...] "a cifra negra representa a diferença entre aparência (conhecimento oficial) e a realidade (volume total) da criminalidade convencional, constituída por fatos criminosos não identificados, não denunciados ou não investigados (por desinteresse da polícia, nos crimes sem vítima, ou por interesse da polícia, sobre pressão do poder econômico e político), além de limitações técnicas e materiais dos órgãos de controle social" (SANTOS, 2006, p. 13).
} 
Dito isso, a falta de uma previsão jurídica específica sobre a conduta e, ainda, a ausência de utilização da nomenclatura sobre o fato demonstram sua característica incipiente no campo jurídico, mas revelam também a ocultação no reconhecimento jurídico dessa espécie de lesão aos direitos humanos de crianças e adolescentes, em especial, conforme restou percebido nos julgados, jovens mulheres.

Após a percepção inicial do Superior Tribunal de Justiça passa-se ao aprofundamento dos elementos da conduta do revenge porn, de modo a interconectar as decisões com as construções doutrinárias sobre o tema.

\section{O REVENGE PORN COMO ATO DE VIOLÊNCIA CONTRA A INFÂNCIA}

O parco volume de decisões do Superior Tribunal de Justiça não significa a inexistência do problema em questão, mas já revela um dos motivos pelos quais os pesquisadores que se debruçam sobre o tema adotam uma nomenclatura diversa do revenge porn, a qual aqui é posta como chamariz ao assunto, embora concorde-se com a adoção massiva do termo em inglês NCII ou Disseminação Não Consensual de Imagens Íntimas (VALENTE et al., 2016, p. 6). Essa denominação é mais abrangente e inclui na ótica do estudo situações que não se revestem de vingança ou mesmo de frustração após o fim de um relacionamento, mas toda e qualquer conduta que tenha por objetivo expor a vítima em sua intimidade, especialmente com conotação sexual ou erótica.

Dito isso, reforça-se a concordância com a terminologia internacional, remetendo-se ainda ao termo revenge porn neste estudo como forma de trazer enfoque e atenção à matéria, bem como manter a aderência ao título/tema da pesquisa.

Destarte, a concepção do revenge porn está associada usualmente com a veiculação de imagens ou vídeos de sexo ou nudez, postadas na Internet por pessoas que findaram relacionamentos ou mesmo parceiros sexuais ocasionais, sem a autorização da outra parte (o que remete à palavra vingança contida na expressão) e, por vezes, contendo dados de identificação (nome, endereço, telefone, página de rede social, etc.) (CALVERT, 2015, p. 677).

Em razão de a conduta ser realizada no universo on-line, acaba por gerar reações no sentido de minorar seu impacto, sendo tal postura ainda atrelada à visão de cindir os mundos do "real" e do "virtual", observando-se que pesquisadores alertam para a armadilha metodológica que é manter tal perspectiva (VALENTE et al., 2016, p. 10). Dessa forma, tem-se como pressuposto de compreensão do assunto em pauta a ausência de divisão entre as esferas virtuais e reais, haja vista que as bases normativas e éticas são idênticas, pois em ambos os ambientes se desenvolvem relações humanas (DIAS, 2016, p. 221), bem como se poderia inferir que os efeitos das ações no mundo virtual estendem-se à "vida real" (não há barreira de contenção).

A extensão dos efeitos na Internet é potencializada, tendo em vista que a confecção dos conteúdos é realizada usualmente de forma livre e voluntária, o que disponibiliza materiais íntimos capazes de revelar diversos aspectos pessoais do indivíduo, mas em contrapartida a divulgação dos mesmos conteúdos eróticos não conta com o consentimento da outra parte, objetivando com isso punir as vítimas ou mesmo provocar-lhes alguma espécie de dor e constrangimento (FARIA; ARAÚJO; JORGE, 2015, p. 667). Desse modo, a conduta realizada pelos 


\section{Humanos e}

Democracia

autores tem como finalidade atingir a vítima não somente em sua persona virtual e sim na sua integralidade, ou seja, tanto em seu perfil digital quanto no mundo real, pois se não fosse assim não haveria motivos para divulgação de informações pessoais e contatos diretos da pessoa exposta nas imagens e vídeos.

Esse prisma delineia que a prática do revenge porn, conforme afirmam Faria, Araújo e Jorge (2015, p. 661), encontra seu elemento mais impactante não na revelação da nudez ou do ato sexual e, sim, na quebra de confiança que expõe a perda do controle sobre o próprio corpo e, desse modo, atinge o ser humano em sua intimidade ou na própria concepção subjetiva e objetiva (pública) ao mesmo tempo.

A perda do controle sobre a intimidade e a vida pessoal, entretanto, causa uma corrente de danos à pessoa exposta, visto que além das possibilidades de ataque virtual, a divulgação de informações pessoais possibilita que as invasões se concretizem em ações diretas, como perseguições ou até mesmo violações de ordem sexual. Demonstrações disso podem ser observadas em ao menos dois dos julgados pelo Superior Tribunal de Justiça, mais especificamente os casos 1 e 4, que apresentam igualmente atuações dos autores in concreto, denotando que além das proliferações de materiais privados das vítimas, também ocorreram ameaças e coerções para retomadas de relacionamentos ou até mesmo para a prática de atos sexuais ou libidinosos (BRASIL, 2014a, 2015b).

O contexto anteriormente descrito revela dois aspectos nucleares da conduta: a) a necessidade de reconhecimento do revenge porn como forma de violência; b) os efeitos concretos sobre as vítimas para além da exposição da intimidade on-line e como tais fatos ampliam o sofrimento produzido pela conduta.

Quanto à primeira afirmativa, registra-se que há resistência por parte de pesquisadores que não acreditam que se possa categorizar as incursões on-line como violência. Ainda assim, contrapõe-se a tal concepção de violência, a qual é entendida como limitada, pois se trabalha com a compreensão ampla de violência, englobando desde aspectos físicos até psicológicos, em especial quando se tem um estudo focado no público infanto-adolescente (BINS; PANICHI; GRASSI-OLIVEIRA, 2016, p. 333-335).

Outrossim, ao tratar a violência de forma abrangente pretende-se convergir nuances de violência física, sexual, psicológica, entre outras variações, para o mesmo denominador comum: é imperioso combater práticas que violem direitos humanos de crianças e adolescentes. Tendo como base a visão de que o ambiente da Internet não passa de outro ambiente para relações humanas, novas formas de violência são capazes de se concretizar neste local, de maneira que a mutação das práticas deve ser acompanhada pela transformação conceitual do que pode ser concebido como violência. Até mesmo porque ao ignorar os danos causados ao infante por condutas violentas (em todos os seus níveis), compromete-se forçosamente o seu processo peculiar de desenvolvimento e, mais especialmente, sua saúde (seja física ou mental) (BINS; PANICHI; GRASSI-OLIVEIRA, 2016, p. 332).

Não bastasse tal linha argumentativa, aduz-se também que existem razões simbólicas na declaração de ações como o revenge porn como violentas, posto que "existe aparentemente um efeito performativo no nomear tais práticas como violentas, que é chamar para a questão da atenção que a cultura dá para tudo aquilo que é proibido, transgressor, ilegal" (VALENTE et al., 2016, p. 13). 
Estabelecidos os sustentáculos para a consideração dos atos na Internet como forma de violência, impõe-se o comento da segunda faceta citada, mais precisamente os efeitos sobre a vítima e a sua amplitude de concretizações. Assim, os relatos embora recentes já são capazes de traçar contornos bastante drásticos ao revenge porn, haja vista que as vítimas relatam situações de perseguição (stalking), queda nas oportunidades de trabalho e de inserção educativa, danos psicológicos. Igualmente, as vítimas que padecem com violência doméstica e agressões sexuais, as pessoas que sofrem com o revenge porn "sofrem consequências negativas ao falar sobre o assunto, incluindo o risco de aumento dos danos" (CITRON; FRANKS, 2014, p. 2, tradução nossa).

Colaciona-se aos danos sofridos o fato de que as atuações jurídicas estão compreendendo há pouco tempo a dimensão devastadora que mídias globalizadas como a Internet podem alcançar na proliferação de imagens e vídeos sem o consentimento (CITRON; FRANKS, 2014 , p. 2). Essa acepção é verificável no plano jurisdicional brasileiro ofertado, tendo em vista que situações como os casos 4 e 6 (BRASIL, 2016b) deixam evidenciado o alcance global da rede mundial de computadores, destacando-se que em uma das situações não se conseguiu ao menos a retirada do material on-line, em razão de o site se hospedar fora dos limites territoriais brasileiros (BRASIL, 2015b).

Por óbvio que no Brasil já foram noticiados casos trágicos envolvendo consequências ainda mais graves sobre adolescentes vítimas da conduta em debate, motivando até mesmo casos de suicídio. ${ }^{2} \mathrm{~A}$ abordagem de tais fatos, porém, recomendaria um estudo específico, o que por ora torna-se inviável, dentro dos padrões estabelecidos, mas ainda assim cabível de menção.

A problematização do revenge porn e a melhoria constante na resposta jurídica para suas consequências deve se dar para evitar a simplificação do problema, ou seja, uma redução significativa ao debate sobre o consentimento ou não de uma das partes envolvidas, gerando com isso posturas contumazes em outras espécies de violência sexual (especialmente contra mulheres), por exemplo, a culpabilização da vítima.

O que aparece como especialmente cruel nos fenômenos envolvendo o revenge porn é o frágil limiar entre o incentivo à exposição enquanto corpo feminino, aí incluídas as próprias demandas feitas por setores do movimento feminista em torno de temas como a representação autônoma de corpos em redes sociais, e a exposição que destrói vidas. Situar esse limiar no consentimento seria uma forma de lidar com a questão, bastante afeita, aliás, à lógica jurídica, mas é simplista. Como veremos adiante, ao lidar com os casos, o consentimento traz consigo um elemento de autonomia importante, mas, em sociedades marcadas pelo sexismo, não é somente a exposição não consentida que pode trazer consequências negativas à vida de mulheres (VALENTE et al., 2016, p. 17).

Nesse norte tal reflexão é valiosa sob dois aspectos diferentes, o primeiro do ponto de vista de que a simplificação que busca ocultar a complexidade ${ }^{3}$ como elemento social a ser inserido na interpretação contemporânea dos problemas jurídicos é extremamente prejudi-

\footnotetext{
${ }^{2}$ Nesse sentido são expostos alguns desses casos concretos no artigo das autoras Faria, Araújo e Jorge (2015, p. 669-671).

${ }^{3}$ A noção de complexidade encontra-se amparada nos estudos de Morin e Le Moigne, de modo a compreender a ciência para além do pensamento cartesiano e da simplificação da realidade, sendo que a complexidade se faz também necessária à compreensão contemporânea dos fenômenos sociais e jurídicos (MORIN; LE MOIGNE, 1999, p. 27-28).
} 


\section{Democracia}

cial à real compreensão das questões criminais que atingem a infância, bem como em um segundo viés reduzir as violações de direitos de crianças e adolescentes à vertente singular do consentimento é ignorar todo o aporte jurídico da infância que direciona no sentido da proteção integral (COSTA, 2011, p. 857-858) e dos compromissos constitucionais de combate à violência contra infantes, os quais por vezes nem ao menos possuem o desenvolvimento juridicamente adequado para consentir com atos de tamanho dano a sua personalidade, sexualidade e dignidade humana.

Até mesmo porque a redução do debate à vertente do consentimento revela um comportamento usual de outros crimes de ordem sexual, nos quais se interpreta o consentimento da vítima para uma conduta em determinado contexto (retratação do ato sexual de forma privativa), como forma de consentir para outras ações em contextos diversos (exposição do conteúdo on-line), algo tipicamente encontrado em alegações de autores de abusos sexuais ou estupros (CITRON; FRANKS, 2014, p. 2).

Cabe breve menção com base tanto no Caso 6 julgado pelo Superior Tribunal de Justiça (BRASIL, 2016b) quanto no suporte de pesquisas sobre o tema em apreço (VALENTE, 2016, p. 23), que apesar de o presente estudo não estar se concentrando em pessoas maiores de idade, existe a manifestação das dificuldades de movimentação e imputação criminal por parte das vítimas do revenge porn, tendo em vista que grande parte das condutas imputadas são revestidas de menor potencial ofensivo e dependem, muitas delas, da atuação privada, tal como ocorre nos crimes contra a honra (isso sem atentar para os crimes que dependem de representação em ação pública condicionada).

No tocante ao aspecto de persecução penal, o fato de atingir crianças e adolescentes traz uma singela facilitação aos órgãos públicos, pois se imputam infrações penais de ação pública incondicionada, as quais estão previstas no Estatuto da Criança e do Adolescente, juntamente aos crimes previstos na codificação penal. Isso pode ser observado nos julgados do Superior Tribunal de Justiça quando se apontam condutas previstas nos artigos 241 (A, B e D) (BRASIL, 1990), em especial a pornografia infantil, a qual nem mesmo os países com vasta tradição na defesa da liberdade de expressão protegem qualquer discurso ou veiculação que atinjam ou exponham a nudez/sexo com crianças e adolescentes (CALVERT, 2015, p. 681).

Essa "facilidade" na persecução penal, todavia, não se reveste do caráter protetivo à infância, conforme se revela em casos apreciados por outras pesquisas no Brasil, as quais indicam a concentração das decisões na questão do consentimento e igualmente na intenção do agente que realizou a conduta, dado que o objetivo da norma, "de acordo com o magistrado, seria proteger principalmente aqueles que ainda guardam certa inocência nas práticas sexuais, o que não seria o caso da vítima" (VALENTE et al., 2016, p. 42). Merece atenção o fato de que a vítima não consentiu com a divulgação das imagens de conteúdo sexual, mas a suposição de "experiência" de vida e sexual, bem como as cogitações mentais do autor serviram de base para afastar a condenação pelo revenge porn. "Dessa forma, parece que o consentimento pela tomada de imagens e também pela sua disseminação assume diferentes pesos nas decisões, a depender, principalmente, de idade e aparência de idade" (VALENTE et al., 2016, p. 44). 
Isso posto, mesmo que se trate de vítimas com maior grau de vulnerabilidade, no caso crianças e adolescentes, isso não significa uma proteção jurídica mais forte, mas ainda assim é necessário observar as peculiaridades das condutas ao atingirem um público tão particular.

Destarte, como em outros crimes sexuais, em que de modo geral as pesquisas revelam há bastante tempo que as ações se concentram contra mulheres (SCHERER; MACHADO; GAUER, 2011, p. 42), no que toca ao revenge porn contra infantes tal fato se repete, ou seja, as principais lesadas nas condutas são crianças e adolescentes associadas ao sexo feminino (e ao gênero mulher). Essa afirmativa da questão de gênero implicada nas ações em debate está amparada tanto em apreciações internacionais (KITCHEN, 2015, p. 249) quanto em dados nacionais, mais especificamente o relato da ONG Safernet Brasil, que apontava que entre 2012 e 2013 houve um aumento considerável no número de denúncias, e a associação das ocorrências de idade concentrava-se nos públicos entre 18 e 25 anos e jovens de 13 a 15 anos, em que mais de 70\% eram mulheres (FARIA; ARAÚJO; JORGE, 2015, p. 667).

Adicionam-se aos números apresentados os dados mais recentes de crescimento nas ocorrências de divulgação não autorizada de imagens e vídeos íntimos, na qual foi inferido um aumento de quatro vezes em dois anos (ESTADÃO, 2015), bem como no ano de 2016 se atribuiu um aumento de outras condutas (ciberbullying, por exemplo) e uma pequena queda no número de "nudes" (fotos de nudez) vazadas na Internet, segundo a Safernet Brasil (G1, 2017).

A apreciação dos resultados apresentados alinha-se com os julgados analisados no Superior Tribunal de Justiça, ao menos no que se refere ao foco de condutas concentradas sobre as mulheres, sendo asseverada a mesma conclusão de análise quando se especifica para observação de casos de infantes.

Dessa forma, o pornô de vingança não conta com o consentimento de uma das partes e tampouco serve socialmente a finalidades exclusivamente eróticas (algo que seria aceitável dentro de relações consensuais). Ao contrário, sua adoção utiliza de forma contumaz mulheres (COMPROMISSO E ATITUDE, 2016) como vítimas a fim de ameaçar, humilhar ou mesmo retaliar qualquer espécie de frustração com um relacionamento (desde traição até o simples término) (FARIA; ARAÚJO; JORGE, 2015, p. 668).

Apesar de usualmente ser apresentado como uma falha de julgamento ou um "pequeno" erro por parte dos infantes envolvidos, é importante registrar que a utilização de imagens para humilhar ou trazer constrangimento ao parceiro ou ex-parceiro vem sendo uma conduta recorrente por acusados de violência doméstica. Isso indica, no tocante aos adolescentes, ao menos um sinal de que crianças e jovens homens usam a tecnologia e outros meios para perpetuar formas de abuso, perseguição e assédio de mulheres (SALTER; CROFTS; LEE, 2013, p. 302).

Diante dessas características não há como negar o componente de gênero e cultural inerente à perpetuação opressiva à sexualidade das mulheres, sejam elas adultas ou infantes e, ao mesmo tempo, de controle e poder por parte dos homens que acabam por dar continuidade à lógica patriarcal e machista, mas pontualmente atingindo crianças e adolescentes em seu processo de desenvolvimento. Exemplificações disso são levantadas a partir das reações 
aos vazamentos de vídeos e imagens sexuais, os quais costumam gerar um processo de culpabilização da vítima, baseando-se em discursos sexistas e difamatórios sobre as atividades sexuais da pessoa envolvida (FARIA; ARAÚJO; JORGE, 2015, p. 671).

Quando essas reações são projetadas contra crianças e adolescentes que estão em uma fase peculiar de desenvolvimento, os danos podem ser ainda mais graves, uma vez que ao invés de acolhimento e proteção, gera-se afastamento e opressão, contrapondo-se claramente aos ditames do Sistema de Garantias de Direitos da Criança e do Adolescente. ${ }^{4}$ Nesse sentido, segue-se a síntese dada por Valente et al., com base em mais de 90 casos apreciados sobre o assunto no Tribunal de Justiça de São Paulo, e que expõe a relevância das noções de gênero para o entendimento do revenge porn com envolvimento de crianças e adolescentes.

Na esfera penal, entre os casos envolvendo adolescentes (ECA) cujas imagens foram divulgadas na Internet, todos referem-se a mulheres cisgêneras, à exceção de um em que figuram duas travestis. Os elementos importantes para a tomada de decisão dos desembargadores foram: a) se o réu tinha consciência da idade da vitima; b) se o réu foi o responsável pela divulgação das fotos; e c) se as fotos possuem conteúdo pornográfico. Ou seja, por mais que o bem jurídico protegido nesse caso fosse a integridade de vítimas menores que, em sua totalidade, eram mulheres, o foco da argumentação do juiz está quase sempre no réu.

Acrescenta-se na discussão ainda que, na decisão envolvendo as duas travestis, o magistrado demonstra insensibilidade ou desconhecimento em relação a questões de orientação sexual e identidade de gênero. Tratava-se de um caso em que os réus eram um casal de adultos que filmava cenas de sexo explícito entre as adolescentes, chegando a contracenar com elas em algumas ocasiões. Durante a descrição do caso, o desembargador chegou a falar que se tratavam de dois adolescentes "transvestidos de mulher", e que uma das vítimas havia admitido que "desde os dez anos tinha comportamento homossexual". O desembargador, ao esclarecer o que significaria o termo "drag", define-o como pessoa do sexo masculino que se passa por uma do sexo feminino "como um dragão, isto é, serpente com o corpo coberto de escamas". Em outros momentos, ao julgar a questão da corrupção de menores, o magistrado passa a impressão de que estaria apreendendo a gravidade da conduta em função de o sexo entre dois homens ser mais degradante do que práticas não homoafetivas (VALENTE et al., 2016, p. 54).

Essa espécie de decisão revela a particularidade contida no tema e que acaba por ser ignorada. Em resumo, com base nas decisões do Superior Tribunal de Justiça ou no relato de pesquisas em outros tribunais, o que se verifica é uma baixa reflexão sobre os detalhes do revenge porn, tais como a vulnerabilidade maior por parte das mulheres, com destaque aqui para crianças e adolescentes, bem como os prejuízos gerados pela não declaração formal do problema (utilização da nomenclatura), juntamente a um enfrentamento diferenciado em sede criminal ou ao menos a consideração crítica sobre o assunto. $O$ último aspecto citado, inclusive, perpassa o debate sobre o uso simbólico dos instrumentos penais e a adequada resposta protetiva a públicos vulneráveis.

\footnotetext{
${ }^{4}$ Para melhor compreensão do funcionamento do Sistema de Garantias de Direitos da Criança e do Adolescente, indica-se a verificação de Custódio (2009, p. 31).
} 
Isso confirma que a obscuridade do revenge porn na condição de problema relevante e que possui camadas profundas nas relações com crianças e adolescentes, que vão desde elementos jurídicos "simples", como o consentimento, até facetas complexas, como as questões de gênero (que deixam claro, por vezes, um discurso moralista contra condutas perpetradas por jovens mulheres), revela a necessidade de aprofundamento no seu estudo. Igualmente evidencia-se a carência pela capacitação dos profissionais jurídicos (sejam eles desembargadores ou ministros do Superior Tribunal de Justiça) para adequada apreciação das situações concretas, a fim de com isso evitar que o Direito sirva de extensão do processo de violência contra crianças e adolescentes e realmente desempenhe o papel de proteção de direitos humanos, ao invés de replicar processos de opressão e preconceito social.

\section{ENFRENTAMENTO DA CRIMINALIDADE CONTRA CRIANÇAS E ADOLESCENTES NA INTERNET: SEXTING, CIBERBULLYING, REVENGE PORN E NOVAS FORMAS DE VIOLÊNCIA ON-LINE}

Após evidenciar as respostas jurisdicionais do Superior Tribunal de Justiça e algumas das formas com que os direitos humanos de crianças e adolescentes acabam sendo atingidos pelo revenge porn e, por conseguinte, pelas próprias repostas à conduta, cabe traçar alguns parâmetros acessórios que circundam a proteção desses direitos na esfera digital. Significa dizer que o entendimento sobre outras condutas similares ou correlacionadas é relevante para compreender o nível de afetação dos direitos humanos dos infantes, bem como auxiliar na definição de estratégias de proteção desses mesmos direitos.

Com base nisso, referencia-se a visão sobre a Internet como mecanismo de comunicação diferenciado, uma vez que costuma ser indicado como um novo paradigma tecnológico (CASTELLS, 2005, p. 108-109), tendo em vista o seu impacto para o viés informacional social atual. É relevante pautar esse entendimento, em especial, pelo nível de inserção dos infantes com essa nova ferramenta, haja vista que os públicos mais jovens costumam ocupar uma fatia mais abrangente quando observados os usuários da rede mundial de computadores (IBGE, 2013, p. 34), além de que, a relação com o mecanismo é completamente diversa dos demais, por se tratar de um meio de autocomunicação de massa (CASTELLS, 2009, p. 88), em que não existe somente um emissor e outro receptor (comunicação de massa usual), mas sim um processo de intercomunicação, trocas constantes de contato e possibilidade contributiva com o próprio desenvolvimento da rede.

Devido à adesão massiva de jovens ao uso da Internet faz-se necessária a projeção de estratégias de proteção de direitos neste plano, pois a inserção neste ambiente é peculiar, inexistindo habilidades "naturais", ou seja, o comentário popular de que os nativos digitais teriam maiores habilidades do que outras pessoas não passa de uma falácia, posto que pesquisas indicam que as habilidades dos infantes variam segundo a condição socioeconômica, bem como se desenvolvem na navegação conforme sua idade vai progredindo (CETIC, 2015, p. 157). Isso indica que a defesa dos direitos humanos de crianças e adolescentes on-line não pode ficar a cargo única e exclusivamente de suas possibilidades de autodefesa ou mesmo sobrecarregando a educação digital como solução "milagrosa" que traria habilidades aos infantes para protegerem sua privacidade e repelirem qualquer ataque criminoso. 
Os riscos existentes, contudo, visto que a criminalidade digital é uma realidade que se expandiu juntamente com o uso da rede mundial de computadores, adotando novas formas e modalidades (LUÑO, 2006, p. 93), não pode servir como impedimento ao acesso à informação e, desse modo, impedir os benefícios advindos da inclusão digital. Ademais, mesmo em temas de ordem sexual esse tipo de espaço de comunicação é valioso ao desenvolvimento de crianças e adolescentes, pois propicia a participação em fóruns e conversações acerca de sua sexualidade (além das próprias identidades) e possíveis dúvidas advindas de suas atividades (SALTER; CROFTS; LEE, 2013, p. 302).

Posto isso, não deve existir uma barreira de cunho moral a impedir o acesso a informações ou mesmo o debate de infantes sobre o assunto, sob pena de frear o desenvolvimento (limitação da curiosidade), o aprendizado ou mesmo os limites das atividades que realizam, ou seja, não há impeditivo no conteúdo, a questão é a forma de tratar esse mesmo conteúdo, bem como o estágio de desenvolvimento do infante para compreender a complexidade do tema. Nesse sentido encontra-se a classificação indicativa no Brasil, pois não há restrição a questões ligadas ao sexo e sexualidade, apenas existem faixas determinadas conforme a densidade de compreensão de determinados assuntos.

Afirma-se o aspecto de conteúdo para que a preocupação sobre o tema do revenge porn não sirva como escusa para nenhuma espécie de cruzada moral ou de retrocesso na inclusão digital da infância.

Dito isso, vislumbra-se que o ambiente on-line é capaz de produzir condutas diferenciadas e tal fato estende-se tanto aos atos lícitos quanto ilícitos. Nesse contexto, seguindo as concepções contemporâneas o revenge porn, tanto quanto outras condutas contra infantes na rede, encaixam-se na concepção de cibercrimes, posto que ocorrem em um ambiente aberto de comunicação, conhecido como ciberespaço, e tendo a Internet como elemento essencial dentro da visão das novas tecnologias da informação e comunicação (LLINARES, 2012, p. 37).

O componente on-line, entretanto, oferta aos cibercrimes peculiaridades, as quais precisam ser compreendidas a fim de evitar prejuízos na tentativa de resguardo de direitos na Internet. Logo, significa dizer que a investida contra o revenge porn não pode ser projetada com base na intervenção penal usual, ou seja, ainda resguardada no plano da territorialidade, por exemplo (TERUELO, 2011, p. 16), visto que os cibercrimes não respeitam as barreiras definidas pelos Estados e suas leis, realizando ações articuladas por vezes em mais de um país, contando com a ausência de previsões em alguns desses locais como forma de burlar a ações criminais.

Outro fator ligado às violações contra a infância on-line está no anonimato presente na Internet e, por mais que se alegue que a Constituição proíbe esse tipo de postura, haja vista que protege a liberdade de expressão e ao mesmo tempo veda o anonimato (BRASIL, 1988), isso não gera um efeito automático sobre as atitudes perpetradas na Internet. Em resumo, por mais que existam proibições legais, inclusive na base legislativa nacional, tal normativa não é capaz de modificar as atuações dos usuários na rede.

Nesse sentido, o anonimato na Internet é relatado como gerador de efeitos danosos, sendo claramente exposto por meio dos casos de revenge porn (STROUD, 2014, p. 169) contra crianças e adolescentes. Ademais, além do abuso da liberdade constitucional, adota-se o ano- 
nimato como estratégia para violar os direitos humanos de personalidade dos infantes (privacidade, imagem, honra), de modo a revelar os lados mais obscuros dos autores, ignorando todas e quaisquer "diretrizes éticas, a moral e os princípios seguidos no mundo físico, real, tornam-se absortos na Internet" (SIRVENT; OLIVEIRA; BENDELLI, 2006, p. 158).

Além das lesões aos direitos humanos evidenciadas, ocultam-se em geral os fatores técnicos que possibilitam o uso do anonimato e que tornam obsoleto o modo ordinário de persecução de crimes como o revenge porn. Demonstrações disso são expostas por Glenny, que explica as duas maneiras mais comuns de esconder a localização física do autor de cibercrimes: a) rede virtual privada ou VPN, "que faz com que um número de computadores partilhe o mesmo endereço IP", de maneira que a localização comum de um usuário por máquina torna-se inútil; b) bem como é possível utilizar os servidores proxy, dado que estes vão confundir a localização, por exemplo, "um computador nas Ilhas Seychelles pode estar usando um proxy na China ou na Guatemala. O proxy não revela que o IP original está transmitindo a partir das Seychelles - mas seja como for o computador faz parte de uma VPN centrada na Groelândia" (GLENNY, 2011, p. 16-17).

Salutar referir que os modos de atuação oculta nem ao menos incluem aqui o uso de criptografia e outras formas de preservação de dados, as quais atualmente estão difundidas em programas públicos (2011, p. 17).

Somam-se às dificuldades operacionais apresentadas, em especial nas situações que tocam o revenge porn, o fato de que embora existam restrições de conteúdo de sites, aplicativos e redes sociais (Facebook, Instagram, WhatsApp), os quais são bastante utilizados pelos infantes, ${ }^{5}$ deve-se ter em mente que após a inserção on-line, dificilmente se aufere a eliminação completa dos materiais postados, seja pela atuação individual de usuários (basta que um deles tenha baixado o conteúdo) ou mesmo pelo rastro digital deixado pelos dados até o dispositivo original (FARIA; ARAÚJO; JORGE, 2015, p. 666-667).

Quando se observa tal aspecto em consonância com o revenge porn envolvendo infantes, mesmo com a pressão judicial pela exclusão das imagens ou vídeos e, por vezes do próprio local de hospedagem desses conteúdos (o site em si), o que é mais provável que aconteça é que o site reabra em um novo servidor ou com outro nome, ou seja, depois de postar fotos ou vídeos íntimos sem o consentimento da outra parte é muito difícil assegurar a sua exclusão perpétua ou ainda a não repostagem por parte de outros usuários (STROUD, 2014, p. 171).

Com fulcro no caráter custoso no processo de eliminação de imagens e vídeos on-line é que se estruturam diversas campanhas de conscientização de jovens sobre as consequências dos atos realizados na Internet. Dessa forma, as tentativas pedagógicas de alguns países vêm ocorrendo na direção de apresentar os efeitos destrutivos de ações como o revenge porn, juntamente com a ênfase sobre as consequências legais advindas (SALTER; CROFTS; LEE, 2013, p. 308).

\footnotetext{
${ }^{5}$ Nesse sentido verificar o incremento no uso de aparelhos móveis, os quais permitem a conexão constante dos jovens às redes sociais e aplicativos, bem como o aumento no uso diário da Internet por parte de crianças e adolescentes, conforme relata a pesquisa do Cetic (2015).
} 


\section{Democracia}

Nesse sentido, parece claro como se inferiu que a proposta educativa isolada não é capaz de solucionar a questão, haja vista a sua complexidade, mas é inegável o seu papel contributivo para o desenvolvimento da infância. Tais procedimentos pedagógicos, contudo, não estão livres de erros, como ignorar os aspectos de gênero ou mesmo generalizar contenções da sexualidade latente.

As críticas citadas podem ser observadas quando se adentra nas campanhas sobre o sexting, conduta essa ligada a diversos casos de revenge porn, seja por sua proximidade ou mesmo pelo assessoramento entre as condutas. Indica-se a aproximação tendo em vista que o sexting se configura pela troca de imagens (sensuais, de nudez) ou vídeos íntimos entre indivíduos, podendo ser eles parceiros sexuais ou não, mas sempre realizando tais câmbios de forma consensual (FARIA; ARAÚJO; JORGE, 2015, p. 667). ${ }^{6}$ Essa criação e troca de conteúdos de ordem sexual, usualmente realizada por telefones móveis (celulares/smartphones) (RINGROSE et al., 2013, p. 2), além de ser uma prática regular realizada por jovens, configura-se por vezes em um ato prévio à realização do revenge porn, visto que o conteúdo já se encontra de posse de um sujeito, bastando a ele apenas a divulgação do material.

Assim, retomando-se a nuance sobre as campanhas educativas, as conscientizações anti-sexting costumam operar um discurso no sentido de responsabilizar a pessoa que produz ou envia a imagem e não a que recebe (e publiciza), ocasionando uma culpabilização da vítima. Desse modo acaba-se por gerar um sentido de contenção moral de jovens mulheres, mas não dos "garotos" (RINGROSE et al., 2013, p. 3).

Logo, a faceta negativa constatável no âmbito internacional merece consideração, pois a fim de evitar tal repetição em sede nacional deve-se ter em mente os aspectos de gênero. Igualmente, pontua-se que a leitura cultural que estimula comportamentos violentos por parte dos homens acarreta efeitos diretos sobre o desenvolvimento de crianças e adolescentes, de modo que as campanhas educativas devem auferir, além do objetivo primário de prevenir as violações de direitos humanos, também desconstruir o padrão que mantém jovens mulheres como alvo preferencial e costumeiramente menos protegido nas dinâmicas do Sistema de Garantia de Direitos (o que inclui as atuações judiciais).

Assim sendo, a fim de impedir que condutas como sexting e o revenge porn se potencializem nos danos aos direitos humanos de infantes, a educação digital é essencial, mas somente se for realizada a partir da desconstrução dos paradigmas de opressão e não como mero reforço punitivo. Ademais, ainda em relação ao sexting, constata-se a crítica no sentido da contradição existente entre o constante confronto de imagens idealizadas do que seria "sexy" para corpos femininos e masculinos, e ao mesmo tempo esses mesmos adolescentes se defrontam com contenções e restrições a sua produção dessas imagens (RINGROSE et al., 2013, p. 3).

\footnotetext{
${ }^{6}$ Em sentido análogo colaciona-se a concepção trazida por Salter, Crofts e Lee (2013, p. 301): 'Sexting' is a term widely used to describe emails, text messages and other forms of electronic communication that contain sexual material, such as a suggestive or provocative text, or images of people who are nude, nearly nude or that are sexually explicit (RINGROSE et al. 2012). Self-produced erotic images and movies circulate widely throughout online and mobile phone networks, but the participation of minors in the self-production and distribution of such material has been the focus of considerable media attention and social concern.
} 
A contradição enfrentada por crianças e adolescentes explica a dificuldade em compreender os danos do sexting, uma vez que tal prática coaduna-se com diversas produções midiáticas a que estão submetidos e de algum modo estimulam a exposição da sua sexualidade. Esse fato acaba tendo como resultado o crescimento do número de casos de sexting no Brasil, alguns igualmente ao revenge porn, tendo consequências irreversíveis (VALE, 2011, p. 114-115).

Não obstante, é salutar aduzir o raciocínio feito por Vale e que serve a ambas as condutas já discutidas, no sentido de dizer que mesmo em caso de renunciar a direitos humanos ou fundamentais utilizando-se da sua autonomia, um sujeito (adulto ou infante) não pode com tal renúncia violar a dignidade humana "porquanto ferem um núcleo essencial e indisponível da pessoa humana, levando à coisificação" (VALE, 2011, p. 123). Menciona-se a argumentação anterior tendo em vista a conexão ensejada entre consentimento e renúncia de direitos, motivo pelo qual se vislumbra esta vertente de pensamento como fundamentação para escusar a responsabilidade dos autores de crimes digitais contra crianças e adolescentes.

Dito isso, é importante referir que inexiste atenção em sede nacional ao tema (afirma-se isso no sentido interno na falta de concentração de políticas públicas e também na ausência de ações coordenadas internacionalmente para minorar os danos on-line a infantes), não havendo uma estratégia ampla de como lidar com a questão. Pontua-se essa feição em razão de que nas relações contemporâneas entre crianças e adolescentes, a troca de mensagens tem um papel central, o que em diversas ocasiões tem a conotação sexual e acaba direcionando a atenção de pais, responsáveis e atores do sistema da infância para como tais infantes utilizam os aparelhos celulares e suas funcionalidades (LENHART, 2009, p. 4).

O quadro delineado demonstra tanto a dificuldade em âmbito teórico-jurídico, operacional e das próprias respostas ofertadas para lidar com as questões da criminalidade digital contra a infância, gerando por vezes resultados estranhos à gravidade das ofensas, como aduz Lenhart (2009, p. 5) ao referir a criação de legislações de Estados americanos que buscam definir como um delito mais "leve" o sexting (e quem sabe até mesmo o revenge porn) quando realizado entre crianças e adolescentes. Por óbvio que alguns dos envolvidos no assunto no plano legislativo já tenham percebido os efeitos danosos que são causados pela rotulação social advinda do estigma do "criminoso", mesmo que este seja um "menor de idade", mas provavelmente essa não é a única motivação para tal alteração, sendo mais provável que as razões estejam situadas em sede de "quem realiza a conduta?" ou "quais adolescentes seriam os autores desses 'crimes'?", o que indicaria um contexto de infantes de classe média ou alta na sua grande maioria (BARATTA, 2002, p. 88).

Essa observação vinculada ao pensamento criminológico crítico é imperiosa para não criar uma ilusão protetiva ou um uso performativo do discurso da proteção integral da infância como subterfúgio para assegurar um tratamento diferenciado a determinadas classes sociais (BUDÓ, 2013, p. 41). Outrossim, tal linha de raciocínio é ainda mais forte quando se traz a criminalidade digital para o plano nacional, visto que embora exista a proliferação no número de jovens usuários, os maiores detentores de alta tecnologia (que vai desde os aparelhos utilizados até a velocidade de conexão) encontram-se nas classes mais altas da sociedade. 


\section{Democracia}

Posto isso, há por parte das práticas do sexting e do revenge porn conexão fática facilmente reconhecível, porém resta à última conduta on-line um perfil diferenciado, a qual se encontra mais ligada aos efeitos resultantes da prática das condutas anteriores, e que se nomeia como ciberbullying. Existe por dedução uma inegável ligação com a conduta do bullying, o qual é conhecido por contar com "atos, palavras ou comportamentos prejudiciais intencionais e repetitivos", observando-se que esses comportamentos são diversificados, indo desde palavras ofensivas, humilhação pública até agressões físicas (MIDDELTON-MOZ; ZAWADSKI, 2007, p. 21).

Tanto na vertente digital quanto na fática é considerável novamente o componente histórico-cultural que "normalizava" ofensas desse gênero, dado que durante largo período essas condutas não foram vistas como graves ou lesivas, sendo compreendidas como parte essencial da infância. "Nas duas últimas décadas, no entanto, essa visão mudou; atualmente o bullying que ocorre nos pátios das escolas e o ciberbullying são vistos como problemas graves que requerem atenção" (SHARIFF, 2011, p. 33).

Ao inserir imagens ou vídeos íntimos sem o consentimento da outra parte (sexting ou por revenge porn), crianças ou adolescentes acarretam efeitos para além do universo jurídico-criminal, ocasionado importunação e humilhação a outra pessoa, tomando assim a forma do ciberbullying. Essa figura diferencia-se da sua matriz pela utilização de tecnologias, ganhando a conotação do bullying "dissimulado e psicológico, transmitido por meio eletrônico como telefones celulares, blogs e sites na Internet, salas de chat, ambientes MUD e Xangas", além de redes sociais (Facebook, Instagram, Myspace) e sites de compartilhamento de vídeos (Youtube) (SHARIFF, 2011, p. 59).

No contexto do revenge porn a exposição da intimidade do infante, não bastassem os prejuízos já relatados (imagem pública, oportunidades de educação e emprego, etc.), oportuniza também diversos tipos de ataques on-line, desde comentários e e-mails diretos até páginas dispostas especificamente com a finalidade de humilhar e ofender a pessoa exposta.

Assim, a vítima infanto-adolescente da divulgação não autorizada é assolada por incursões lesivas não vinculadas à primeira ação e, por se tratar de um ambiente digital, amplifica-se a sensação de opressão ou de não haver interrupção nos ataques, uma vez que a Internet funciona de forma ininterrupta (BEANE, 2010, p. 131-132). Ademais, o alcance do meio de comunicação é global, de maneira que o ciberbullying ligado ao revenge porn amplia o campo de humilhação ao máximo, haja vista que o "mundo inteiro" é capaz de ver a condição sofrida pela criança ou adolescente.

Adicionam-se ainda os efeitos psicológicos sobre o infante, o qual se encontra em fase de desenvolvimento peculiar, conforme o reconhecimento da própria legislação, mas que está sujeito a aumentar suas chances de patologias psicológicas como "depressão e aos transtornos de ansiedade, em especial o transtorno de estresse pós-traumático" (BINS; PANICHI; GRASSI-OLIVEIRA, 2016, p. 339), em razão do cyberbullying.

Verifica-se que o ciberbullying possui a capacidade individualizada enquanto conduta de gerar seus próprios danos, porém no contexto da pesquisa sua projeção é desencadeada pela disseminação não consensual de imagens ou vídeos íntimos on-line, demonstrando a sua natureza igualmente "cooperativa". Isso indica outras possibilidades na execução da crimina- 
lidade digital contra a infância, por meio da combinação de infrações, e embora seja salutar referenciar que os julgados observados no Superior Tribunal de Justiça não abrangem o nível dos efeitos sociais causados pelo crime em questão, tal fato não significa a sua inexistência.

A partir da lógica de funcionamento do revenge porn, auxiliado pelo sexting quando este é exposto on-line (pois, caso não fosse, poderia, desde que respeitadas as limitações legais, ficar adstrito às expressões e comunicações ligadas à sexualidade), apregoa-se o ciberbullying como um componente significativo no incremento dos danos provocados contra crianças e adolescentes na Internet. De tal modo, a funcionalização de um planejamento específico para a área deveria ao menos ingressar na agenda política (HOWLETT; RAMESH; PERL, 2013, p. 120) vinculada ao Sistema de Garantia de Direitos da Criança e do Adolescente.

Nesse sentido, o pleito pela atenção à criminalidade digital contra a infância, em especial aqui o revenge porn, não vem única e exclusivamente da percepção dos julgados ou dos dados de aumento de denúncias no país sobre o assunto, mas também do relato internacional dos profissionais responsáveis pela persecução criminal de crescimento nas violações de natureza sexual contra estes alvos (MAUR, 1999, p. 102-103). Seja em razão da maior vulnerabilidade ou pelas facilidades que a tecnologia é capaz de oferecer, as incursões lesivas aos direitos humanos de crianças e jovens já superam as ordinárias (mas que já detêm no Brasil um foco de esforço político-jurídico) (DIAS, 2016, p. 252-256) ocorrências de pornografia infantil, ganhando força novas formas de ofensa a sua integridade física e mental.

Diante do exposto, argumenta-se que as soluções almejadas para o problema em questão precisam ir além da educação digital ou da descoberta de novos crimes, devendo perpassar a capacitação/preparação dos próprios profissionais da rede de atendimento (SHARIFF, 2011, p. 327) para que as respostas às demandas da infância tenham a complexidade necessária e não sejam rendidas aos discursos punitivos ou de ódio prolatados atualmente.

\section{CONCLUSÃO}

O debate acerca de novos temas inseridos em plataformas recentes para realização de relações humanas constitui-se em um desafio significativo, mas que traz consigo o aporte constante de preservação de direitos humanos em todo e qualquer espaço. Com base nesse pressuposto, a abordagem do revenge porn quando perpetrado contra crianças e adolescentes, trata-se de uma preocupação relevante ante o cenário de inclusão digital contemporâneo, no qual a capacidade de operacionalização de tecnologias é considerada não apenas parte do aprendizado, mas também uma necessidade na futura inserção no mercado de trabalho ou mesmo na realização de relações interpessoais on-line.

$\mathrm{Na}$ busca por repostas às indagações que atingem o assunto elegido e colocam em posição desfavorável os direitos humanos de infantes, executou-se a reflexão a partir de uma estrutura de pesquisa indutiva, partindo dos julgados realizados pelo Superior Tribunal de Justiça, os quais representam o ponto específico de partida, até as considerações gerais acerca da criminalidade digital em suas mais recentes formas contra a infância no Brasil.

Destarte, tendo por questionamento de pesquisa como os direitos humanos e de que forma eles seriam atingidos pela conduta do revenge porn, e qual seria a resposta jurisdicional a essa demanda, inicia-se o estudo pela leitura dos posicionamentos do Superior Tribunal de 


\section{Democracia}

Justiça, entre os anos de 2014 e 2016, com base em buscas jurisprudenciais de palavras-chave ligadas ao tema. Junto aos elementos de busca citados adiciona-se ainda o componente da infância como polo atingido pela violação penal, visto que esse público apresenta maior vulnerabilidade e ao mesmo tempo um volume maior de inserção on-line, quando comparado à totalidade da população nacional.

Apesar de um retorno pequeno do viés quantitativo, as decisões apresentam características valiosas à construção crítica, de modo que denunciam as dificuldades operacionais de persecução penal, embora tratando-se de crimes de ação pública incondicionada, quando se trata de crianças e adolescentes, bem como resta clara a maior propensão de ataques contra jovens mulheres. As decisões observadas, portanto, reforçam o quadro de violência contra mulheres e, no tocante à infância, isso não é diverso, além de que nenhum julgado utiliza qualquer nomenclatura ligada ao assunto, gerando assim um processo de ocultação do problema.

Nesse sentido, ao debruçar-se sobre o tema do revenge porn e seus estudos mais específicos, observa-se a reiteração das anotações supramencionadas na interpretação doutrinária, ao passo que se incluem outras nuances, como a influência cultural e a profundidade imperiosa ao debate de gênero. As inserções, todavia, não se limitam a conceituar e compreender as características apontadas por estudiosos, mas sim verificar que ao não declarar o revenge porn (ou a nomenclatura mais adequada Disseminação Não Consensual de Imagens Íntimas) nas decisões realiza-se conjuntamente a ocultação da infração penal, bem como do próprio reconhecimento da violência.

Essa negativa a respeito da violência ignora por óbvio as lesões aos direitos humanos, tais como a dignidade humana, privacidade, imagem, honra, liberdade (de expressão e sexual). Ademais, não se reconhece assim o parco arcabouço jurídico na previsão de crimes digitais e os efeitos sociais resultantes da conduta (dificuldades educacionais, de trabalho ou a vulneração a respeito de ataques com violência física).

Após o estabelecimento das bases críticas de leitura do revenge porn e das próprias decisões judiciais nacionais, as quais demonstraram uma simplicidade considerável em uma demanda tão complexa, torna-se possível compreender a amplitude de ações no universo da Internet. Tal consideração ocorre exatamente pela representatividade que os demais crimes digitais executados em conjunto com o revenge porn, como o sexting e o ciberbullying, são capazes de causar a crianças e adolescentes, apresentando uma gama de danos sociais, físicos e psicológicos.

Por fim, as considerações finais de que há um evidente hiato jurídico e político no que se refere ao revenge porn contra infantes, deixando diversos direitos humanos desprotegidos (em franco descompasso com a proteção integral), bem como que as atuais respostas judiciárias deixam a desejar no tratamento dos casos concretos, não são suficientes. Logo, tais conclusões, apesar de incipientes, precisam apontar para um caminho que supere as meras respostas punitivas (novos crimes) ou demagógicas (educação salvadora), de maneira que a densidade do assunto exige a variação nas ações traçadas para lidar com o problema, indo desde capacitação dos profissionais da rede de atendimento até a desconstrução cultural da violência na infância. 
Nesse sentido, a discussão ora ofertada não está encerrada, pois a atenção com crianças e adolescentes em fase de desenvolvimento deve ser constante e, para uma inclusão digital adequada, a preservação dos direitos humanos é essencial, motivo pelo qual se deve evidenciar toda e qualquer prática contra a infância, de modo a impulsionar a melhoria constante do sistema de garantia de direitos e a própria base jurídica que o sustenta.

\section{REFERÊNCIAS}

BARATTA, Alessandro. Criminologia crítica e crítica do direito penal: introdução à sociologia do direito penal. 3. ed. Rio de Janeiro: Revan, 2002.

BEANE, Allan L. Proteja seu filho do bullying. Rio de Janeiro: Bestseller, 2010.

BINS, Helena Dias de Castro; PANICHI, Renata Maria Dotta; GRASSI-OLIVEIRA, Rodrigo. Violência infantil. In: ABDALLA-FILHO, Elias; CHALUB, Miguel; TELLES, Lisieux E. de Borba. Psiquiatria forense de Taborda. 3. ed. Porto Alegre: Artmed, 2016.

BRASIL. Constituição Federal. 1988. Disponível em: http://www.planalto.gov.br/ccivil_03/constituicao/constituicaocompilado.htm. Acesso em: 29 abr. 2017.

BRASIL. Estatuto da Criança e do Adolescente. 1990. Disponível em: http://www.planalto.gov.br/ccivil_03/leis/ L8069.htm. Acesso em: 19 abr. 2017.

BRASIL. Superior Tribunal de Justiça. Habeas Corpus n. 298504. 10 de setembro de 2014a. Disponível em: http:// www.stj.jus.br. Acesso em: 14 abr. 2017.

BRASIL. Superior Tribunal de Justiça. Recurso Especial n. 1475686. 4 de setembro de 2014b. Disponível em: http://www.stj.jus.br. Acesso em: 14 abr. 2017.

BRASIL. Superior Tribunal de Justiça. Habeas Corpus n. 324343. 3 de junho de 2015a. Disponível em: http:// www.stj.jus.br. Acesso em: 15 abr. 2017.

BRASIL. Superior Tribunal de Justiça. Conflito de Competência n. 135455. 30 de novembro de 2015b. Disponível em: http://www.stj.jus.br. Acesso em: 15 abr. 2017.

BRASIL. Superior Tribunal de Justiça. Agravo em Recurso Especial n. 828064 . 30 de março de 2016a. Disponível em: http://www.stj.jus.br. Acesso em: 15 abr. 2017.

BRASIL. Superior Tribunal de Justiça. Habeas Corpus n. 361038. 16 de junho de 2016b. Disponível em: http:// www.stj.jus.br. Acesso em: 15 abr. 2017.

BRASIL. Superior Tribunal de Justiça. Disponível em: http://www.stj.jus.br/SCON/decisoes/toc.jsp?livre=v\%EDdeo+e+ex-namorado\&\&b=DTXT\&thesaurus=JURIDICO\&p=true. Acesso em: 14 abr. 2017a.

BRASIL. Superior Tribunal de Justiça. Disponível em: http://www.stj.jus.br/SCON/decisoes/toc.jsp?livre=interne$\mathrm{t}+\mathrm{e}+$ imagens+int\%EDmas\&\&b=DTXT\&thesaurus=JURIDICO\&p=true. Acesso em: $14 \mathrm{abr} .2017 \mathrm{~b}$.

BRASIL. Superior Tribunal de Justiça. Disponível em: http://www.stj.jus.br/SCON/decisoes/toc.jsp?livre=nude$z+e+v \% E D d e o+e+a d o l e s c e n t e \& \& b=D T X T \&$ thesaurus=JURIDICO\&p=true. Acesso em: 14 abr. 2017c.

BUDÓ, Marília de Nardin. Mídias e discursos do poder: a legitimação discursiva do processo de encarceramento da juventude pobre no Brasil. 2013. Tese (Doutorado em Direito) - Curso de Pós-Graduação em Direito, Universidade Federal do Paraná, Curitiba, 2013.

CALVERT, Clay. Revenge Porn and Freedom of Expression: Legislative Pushback to an Online Weapon of Emotional and Reputational Destruction. Fordham Intellectual Property, Media and Entertainment Law Journal, v. 24, Issue 3, article 2, Book 3, 2015.

CASTELLS, Manuel. A sociedade em rede. São Paulo: Paz e Terra, 2005.

CASTELLS, Manuel. Comunicación y poder. Madrid: Alianza Editorial, 2009.

CETIC. TIC KIDS on-line Brasil 2014: pesquisa sobre o uso da Internet por crianças e adolescentes no Brasil. São Paulo: Comitê Gestor da Internet no Brasil, 2015. Disponível em: http://cetic.br/publicacao/pesquisa-sobre-o-uso-da-internet-por-criancas-e-adolescentes-no-brasil-tic-kids-online-brasil-2014/. Acesso em: 20 abr. 2017.

CITRON, Danielle Keats; FRANKS, Mary Anne. Criminalizing revenge porn. Wake Forest Law Review, 49, rev. 345, 2014.

COMPROMISSO E ATITUDE. Lei Maria da Penha. \#PODEPARAR - Mulheres são principal alvo da pornografia de vingança. 2016. Disponível: http://www.compromissoeatitude.org.br/podeparar-mulheres-sao-principal-alvo-da-pornografia-de-vinganca/. Acesso em: 10 abr. 2017. 


\section{Democracia}

Humanos e

COSTA, Ana Paula Motta. A perspectiva constitucional brasileira da proteção integral de crianças e adolescentes e o posicionamento do supremo tribunal federal. In: SARMENTO, Daniel; SARLET, Ingo Wolfgang (coord.). Direitos fundamentais no supremo tribunal federal: balanço e crítica. Rio de Janeiro: Lumen Juris, 2011.

CUSTÓDIO, André Viana. Direito da criança e do adolescente. Criciúma: Unesc, 2009.

DIAS, Felipe da Veiga. O direito à informação na infância on-line. Curitiba: Prismas, 2016.

ESTADÃO. Em 2 anos, no de vítimas de imagens íntimas vazadas quadruplica - ONG brasileira de defesa de direitos humanos que atua na internet recebeu 224 denúncias no ano passado, ante 48 em 2012. 2015. Disponível em: http://brasil.estadao.com.br/noticias/geral, numero-de-vitimas-de-imagens-intimas-vazadas-na-web-quadruplica-em-2-anos,1719799. Acesso em: 10 abr. 2017.

FARIA, Fernanda Cupolillo Miana de; ARAÚJO, Júlia Silveira de; JORGE, Marianna Ferreira. Caiu na rede é porn: pornografia de vingança, violência de gênero e exposição da "intimidade". Contemporanea - Comunicação e Cultura, v. 13, n. 3, set./dez. 2015.

G1. Cai o no de vítimas de "nudes" vazadas na internet do Brasil em 2016, diz ONG - casos de cyberbullying, por sua vez, cresceram 17,7\%, segundo a Safernet. Disponível em: http://g1.globo.com/tecnologia/noticia/cai-o-n-de-vitimas-de-nudes-vazadas-na-internet-do-brasil-em-2016-diz-ong.ghtml. Acesso em: 10 abr. 2017.

GLENNY, Misha. Mercado sombrio: o cibercrime e você. São Paulo: Companhia das Letras, 2011.

HOWLETT, Michael; RAMESH, M.; PERL, Anthony. Política pública: seus ciclos e subsistemas - uma abordagem integradora. Rio de Janeiro: Elsevier, 2013.

IBGE. Instituto Brasileiro de Geografia e Estatística. Pesquisa nacional por amostra de domicílios - acesso à Internet e posse de telefone móvel celular para uso pessoal (2011). Rio de Janeiro: IBGE, 2013.

KITCHEN, Adrienne N. The Need to Criminalize Revenge Porn: How a Law Protecting Victims Can Avoid Running Afoul of the First Amendment. Chicago-kent law review, v. 90, article 11, 2015.

LENHART, Amanda. Teens and Sexting: how and why minor teens are sending sexually suggestive nude or nearly nude images via text messaging. Pew Internet \& American Life Project. 2009. Disponível em: http://www.pewinternet.org/2009/12/15/teens-and-sexting/. Acesso em: 12 abr. 2017.

LLINARES, Fernando Miró. El cibercrimen: fenomenología y criminología de la delincuencia en el ciberespacio. Madrid: Marcial Pons, 2012.

LUÑO, Antonio Enrique Pérez. La tercera generación de derechos humanos. Navarra: Aranzadi, 2006.

MAUR, Agnès Fournier de Saint. Abuso sexual de crianças na internet: um novo desafio para a Interpol. In: UNESCO. Inocência em perigo: abuso sexual de crianças, pornografia infantil e pedofilia na internet. Rio de Janeiro: Garamond, 1999.

MIDDELTON-MOZ, Jane; ZAWADSKI, Mary Lee. Bullying: estratégias de sobrevivência para crianças e adultos. Porto Alegre: Artmed, 2007.

MORIN, Edgar; LE MOIGNE, Jean-Louis. L'intelligence de la complexité. L'Harmattan: Montreal, 1999.

RINGROSE, Jessica; HARVEY, Laura; GILL, Rosalind; LIVINGSTONE, Sonia. Teen girls, sexual double standards and "sexting": gendered value in digital image exchange. Feminist Theory, 14 (3). p. 305-323, 2013.

SALTER, Michael; CROFTS, Thomas; LEE, Murray. Beyond Criminalisation and Responsibilisation: Sexting, Gender and Young People. Current Issues in Criminal Justice, v. 24, n. 3, March, 2013.

SANTOS, Juarez Cirino. A criminologia radical. Curitiba: IPCP; Lumen Juris, 2006.

SCHERER, Carmen Cabral; MACHADO, Débora Silva; GAUER, Gabriel José Chittó. Uma violência obscura: abuso sexual. In: GAUER, Gabriel José Chittó; MACHADO, Débora Silva. Filhos \& vítimas do tempo da violência: a família, a criança e o adolescente. 2. ed. Curitiba: Juruá, 2011.

SHARIFF, Shaheen. Ciberbullying: questões e soluções para a escola, a sala de aula e a família. Porto Alegre: Artmed, 2011.

SIRVENT, José Francisco Chofre; OLIVEIRA, Álvaro Borges de; BENDELLI, Rachel. Transnacionalidade dos princípios da não-violação de privacidade na internet. Revista Seqüência, n. 52, jul. 2006.

STROUD, Scott R. The Dark Side of the Online Self: A Pragmatist Critique of the Growing Plague of Revenge Porn. Journal of Mass Media Ethics, v. 29, p. 168-183, 2014.

TERUELO, Javier Gustavo Fernández. Derecho penal e internet: especial consideración de los delitos que afectan a jóvenes y adolescentes. Valladolid: Lex Nova, 2011.

VALE, Ionilton Pereira do. O consentimento da gravação e difusão de vídeos de conteúdo sexual em face do estatuto da criança e do adolescente. Revista da Ajuris, v. 38, n. 122, jun. 2011.

VALENTE, Mariana Giorgetti; NERIS, Natália; RUIZ, Juliana Pacetta; BULGARELLI, Lucas. O corpo é o código: estratégias jurídicas de enfrentamento ao revenge porn no Brasil. São Paulo: InternetLab, 2016. 